\title{
PLM Reference Model for Integrated Idea and Innovation Management
}

\author{
Manuel Löwer and Jan Erik Heller \\ Institute for Engineering Design (ikt), RWTH Aachen University, Germany \\ loeweraikt.rwth-aachen.de
}

\begin{abstract}
The authors present their research results and practical experience regarding implementations of PLM systems in a set of companies. In detail, the very early stages of product planning and innovation management are considered. As most of today's enterprises already operate PDMS (Product Data Management Systems), excellent foundations for a company-spanning idea and innovation management exist. An extensive analysis showed that idea management - if established - uses autonomous databases and data models which are not merged into or consistent with already existing PLM models. Potential is scattered due to disruptions in the information flow. Mostly, marketing and strategic groups have no direct access to relevant development and service data and thus lack customer feedback and stimuli for new strategic product ideas. Furthermore, strategic, technological and market boundaries have not been modelled yet to allow for an efficient handling of «postponed » ideas. The authors developed an extended data model in combination with a reference process model for innovation and idea management. Strategic data comparable to business intelligence information is consolidated with regular PLM information offering advanced opportunities and efficiency for innovation management. The paper also features an implementation of the introduced reference data and process models in a state of the art PLM system. Additionally, the approach serves as a guideline for SMEs and enables the set-up of professional innovation and idea management including presets for workflows, model attributes and open innovation functionalities.
\end{abstract}

Keywords: Integrated Product Lifecycle Management (PLM), Innovation and Idea Management, Product Planning and PLM, PLM Reference Model.

\section{$1 \quad$ Introduction}

In today's increasingly fast changing markets, enterprises are constantly forced to come up with fresh ideas and new products in order to remain competitive. In other words, they are forced to innovate. However, the term « innovation » has been one of the most used words during the last years when it comes to strategic product development. But innovation is more than the actual invention since it needs to match economic conditions and requires a successful market launch. Several approaches exist to transform ideas into products, subsumed as innovation management. Even 
though innovation management is implemented by larger enterprises on business process levels, a sustainable integration of reasonable data, information and processes has not been realized. Moreover, SMEs typically lack the financial resources to set up explicit staff positions and introduce broad and comprehensive approaches.

Product lifecycle management offers all means to provide that integrated platform. Per definition, PLM covers all phases of products' lifecycles from ideas to their disposal $[1,2]$. From the authors' perspective, this common understanding of PLM has its limitations since the phase «zero » is improperly addressed. Hence, information about circumstances which led to the initiation of a focused idea development are not recorded and associated with the future product. Affected data mainly includes external or internal needs and strategic considerations which are subject to change rapidly. In addition, it usually needs a large number of ideas for the successful launch of a single product (Fig. 1). This does not necessarily mean that most of the withdrawn ideas in the process have no economic potential.

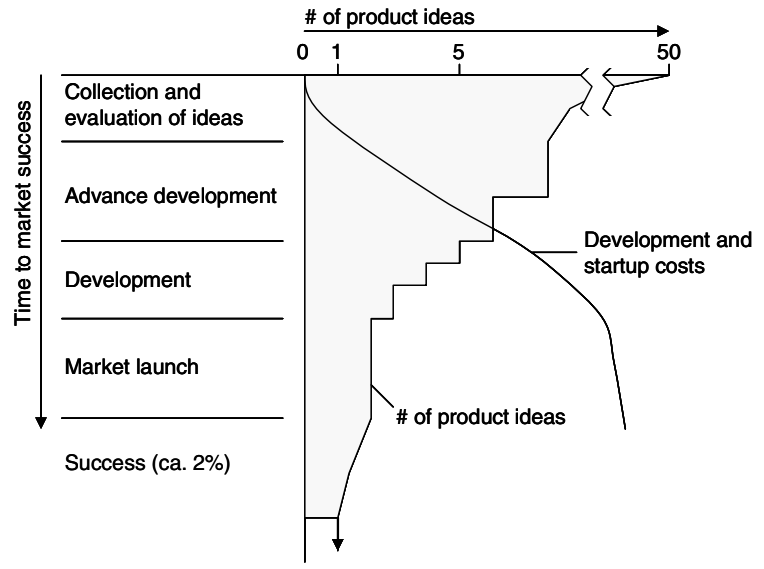

Fig. 1. Reduction of ideas along the innovation process [3]

There is actually a large number of different reasons for not following ideas in a specific innovation cycle, ranging from insufficient company knowledge for needed production technology to currently non-economical commodity prices or even political influences such as punitive tariff duties. Studies show that most of the ideas which are transferred into commercial products originate from the development departments (Fig. 2). Since these divisions are historically constraint to document their work for further processing, engineering or product data management (PDM), in the majority of companies is implemented with the most advanced technical means in terms of process and data management. Thus, the technical availability of such systems can be exploited and broadened to the innovation and idea management affected departments of the company. 


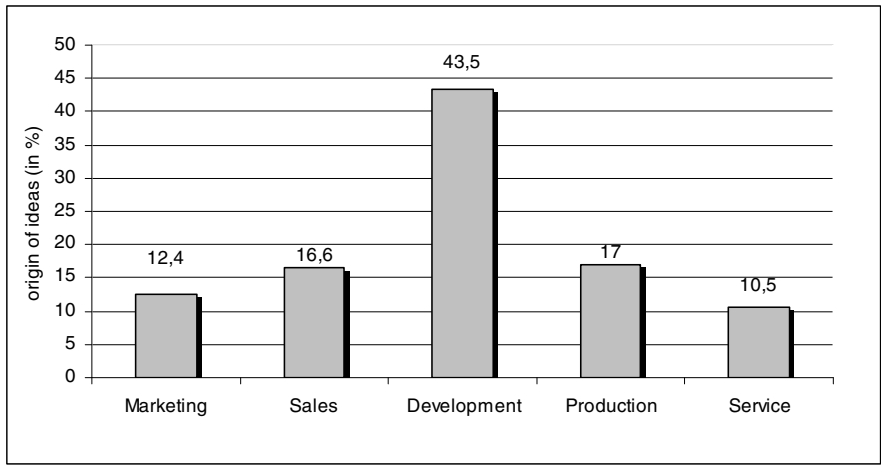

Fig. 2. The origin of product ideas [4]

\section{The Process of Idea and Innovation Management}

The buzzword innovation is frequently misinterpreted as the invention itself. In 1934 Schumpeter already emphasized that innovation describes the transformation of an invention or at least enhancements of existing products into a commercial application for a company [5]. One of the characteristics of this innovation is a so called degree of novelty, which can be subjective or objective and applies to products, services or processes [6]. Regardless of the type of innovation, the driver and catalyst commonly is the acquisition of market shares or the sustainment of the actual position $[7,8]$. Hence, innovation cannot be seen as a nonrecurring, singular activity but rather as a periodic and complex business process which demands for a profound workflow suitable for the particular company. Within such a framework, the innovation management addresses and affects the three different layers: normative, strategic and operational ones (Fig. 3). The normative management sets the boundaries and restrictions for the definition of the innovation management on the strategic layer leading to the innovation targets and a structured innovation program.

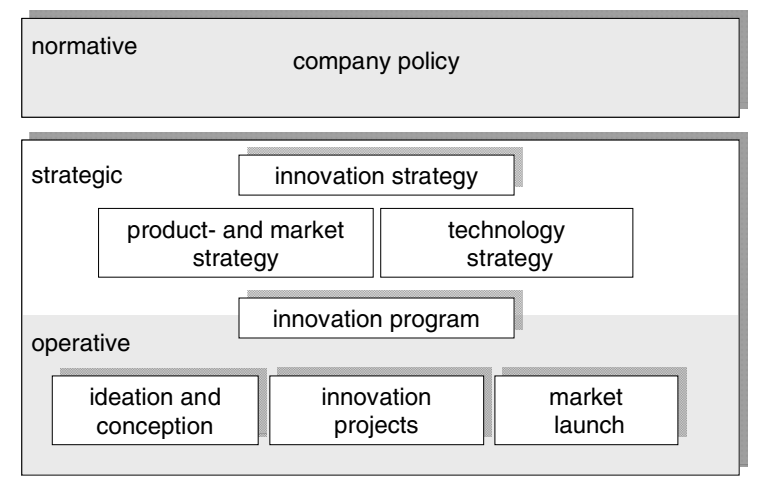

Fig. 3. The framework of innovation management [on the basis of 9,10] 


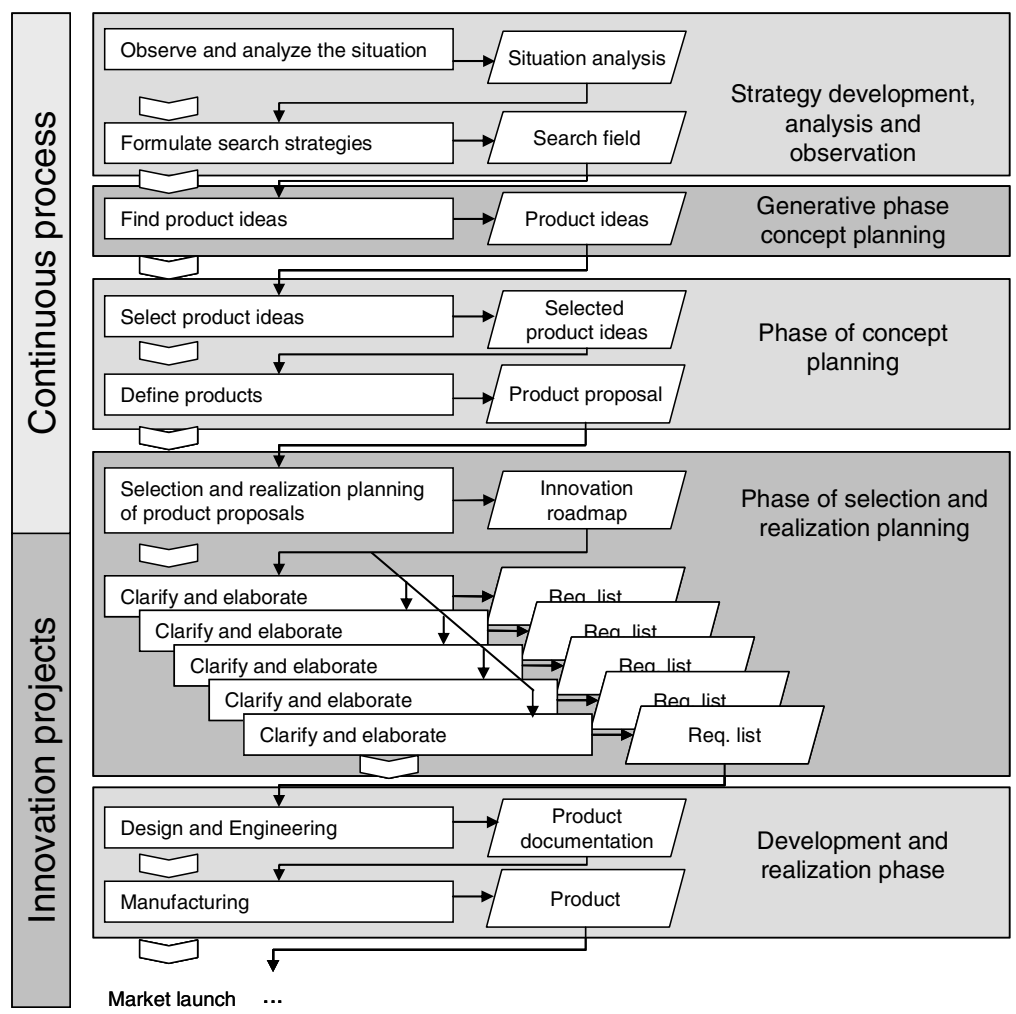

Fig. 4. The process of innovation management

This program is then systematically operationalized with ideation and conceptualization following e.g. the generic process of product planning as provided by VDI2220 and can also be realized within innovation projects also incorporating tools and methods of industrial design. As part of the undertaken research, different innovation processes have been evaluated and basic proceeding was setup (Fig. 4). It should serve as a landmark for the analysis of the own innovation activities. The research has been conducted in line with a set of consulting projects for the introduction and implementation of PDMS at different customers. It turned out that none of them had rather defined nor implemented strategic aspects of product planning. Due to this, the need for a method to introduce a PDM based innovation management arose. This method is presented in the following section of this paper.

\section{A Method for the Introduction of a PDMS Based Innovation Management}

The innovation process is a sequence of deductive acquisition and processing of information. In each step a concretion using different methods and models is achieved. 
Compared to common technical parameters, strategic and normative boundaries are often of descriptive character, not quantifiable and hardly reducible to a single attribute. This complicates the extension of standard PLM data models and an evaluation of prospective costs and efforts in comparison to the anticipated benefit is highly recommended. The developed method (Fig. 5) is divided into three main phases and entails different evaluation milestones to ensure an effective controlling.

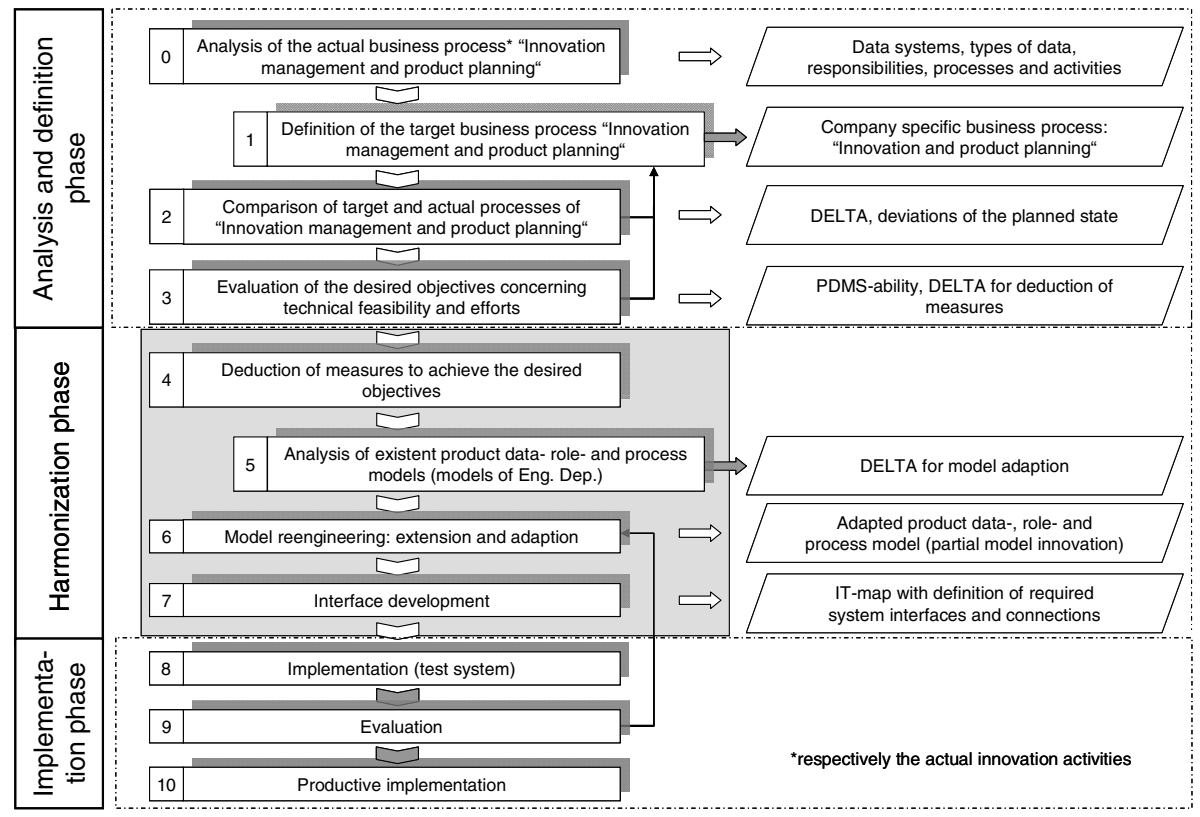

Fig. 5. Method to introduce a PDM based innovation management

The first phase (analysis and definition) closes with a conclusion about the company's needs and ability to deploy a PDM based innovation and idea management, the resulting efforts and the technical feasibility. Within the second phase, measures to achieve the intended state are taken. In most cases this requires a noticeable reengineering of product data, process and role models, assuming that PLM-supporting systems or respectively PDMS are already implemented for a restricted group of users. The third phase starts with the implementation of key functionalities on a test system, followed by different evaluation scenarios. Throughout this whole process the so called Capability Scorecard (CSC) is used that allows for the transition of a PLM strategy into operational activities and a quantifiable assessment of the achievement of objectives [11]. Once the testing has proved positive an implementation in the productive system and roll out can be pursued.

The use of IT systems to support business processes implies the understanding that these systems are not intended to substitute or directly control employees. Acceptance and the success of a later deployment strongly depend on the proper communication of what the clear benefits are for the involved parties in their daily routine. In addition, 
implementing every sub process as a workflow will lead to getting the implementation efforts out of hand and the project to fail.

\subsection{Support of the Continuous Innovation Process}

The following subsection gives an overview of requirements for the IT-based innovation planning and the key objectives.

\section{Capturing and Management of Ideas}

Per definition, ideas have a higher degree of abstraction compared to product concepts. Textual descriptions of ideas are an obvious way to articulate their content and to make them explicitly available. However, a system based evaluation, selection or clustering is not directly made possible through such a description. Additionally, characteristics and criteria such as classification schemes have to be realized to ease the search and identification of suitable ideas for the future user.

\section{Simple Access and Participation in the Idea and Innovation Process}

Globalization and customer awareness set the trend to also enclose external sources and resources in the innovation process. Current PLM and PDMS software generally offers web technologies so that customers, partners or third parties can easily be integrated. Depending on the level of confidence, content has to be restricted trough an advanced role model and rights management.

\section{Monitoring and Evaluation of Innovation Activities}

The association of ideas available in the database to innovation projects and created products should provide a traceable realization rate. Not only the outcome but also the actual status of an idea or project as well as a report of current activities for a specific search field, a business unit or braches should be available in real-time. Financial incentives for top innovation performers or significant sources for good ideas, which can be identified by the system, can be implemented. Integrated project management functionalities provide controlling mechanisms and inform about the innovation costs.

\subsection{Support of Innovation Projects}

As already stated, there can be different initiations for innovation projects. One is the continuous observation of the market or main competitors. Another one can be a specific planned activity or technology push. For both (and additional) cases, a process template has to be defined, providing a suitable framework to guide the user. Beyond project specific data, information from product planning and monitoring of later lifecycle phases has to accessible. 


\section{$4 \quad$ PDMS Centred Innovation Management}

The aspects of PDMS for the usage in the area of idea and innovation management can thus be divided into the core functionalities of innovation planning and controlling, project management and execution as well as idea-, concept- and data management. The different sub functionalities are also depicted in Fig. 6. Data- process- and role model serve as the backbone and ensure the integrated PLM approach. These models should be a digital mirror of the company in terms of its innovation activities and associated data and organizational structures. For those who do not have an established and documented process, the authors set up a process model as a maximum template which covers all relevant activities of innovation planning. The structure allows for a direct utilization for the three business models listed above. To unambiguously describe each process element, several parameters have to be included: process id, superordinate process (e.g. business process), predecessor and successor process, input (data, kind of data, format, location and association to predecessor processes), output, involved parties (groups, roles), responsible instances (process owner and authorized for changes), media and tools needed for the transformation of input to output.

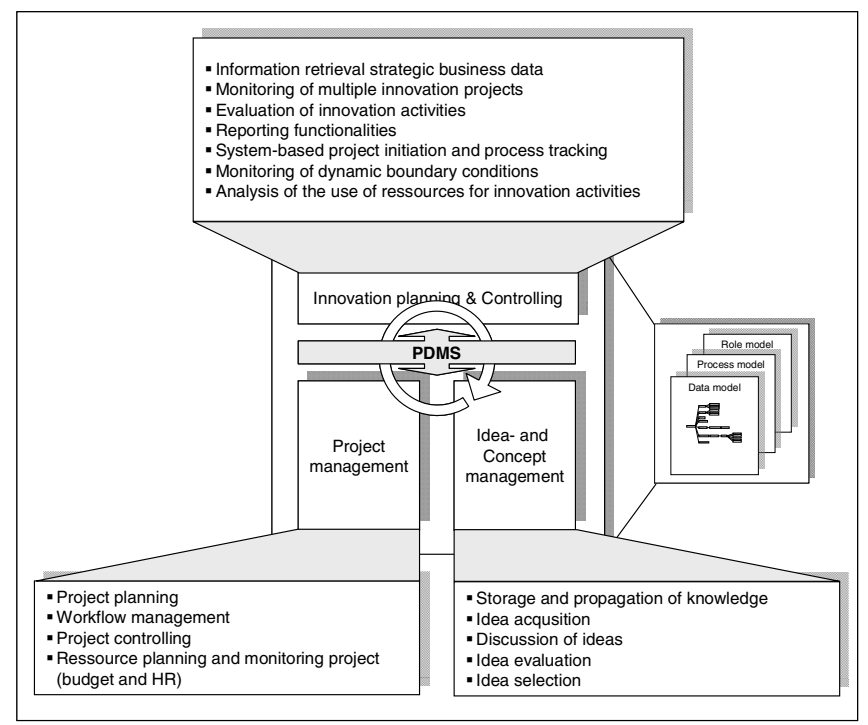

Fig. 6. PDMS centred innovation management [12]

Referring to the product data model the different data objects, their dependencies and attributes have to be analysed. In order to model a PDMS data object also the object lifecycles have to be considered. In addition, the object can contain different objects itself as part of the object master record. These objects can conclusively own attributes. In the previous section of this contribution, it has been emphasized that ideas and the management of ideas is crucial for successful innovation. 
Thus, the data model for the object "idea" to be implemented in a PDMS is described for clarification (Fig. 7). To comprehensively describe an idea and to make it sustainably available in a PDMS, the authors identified the need for integrating different elements: an idea description, a sketch, note/comments, discussion forum and evaluations. For the idea object, these documents or fields constitute the major record. The idea description should be covered as a document to allow for versioning and idea adaption in later phases. This document in turn owns a large number of attributes, and also has different lifecycle stages, the document lifecycles.

object lifecycle

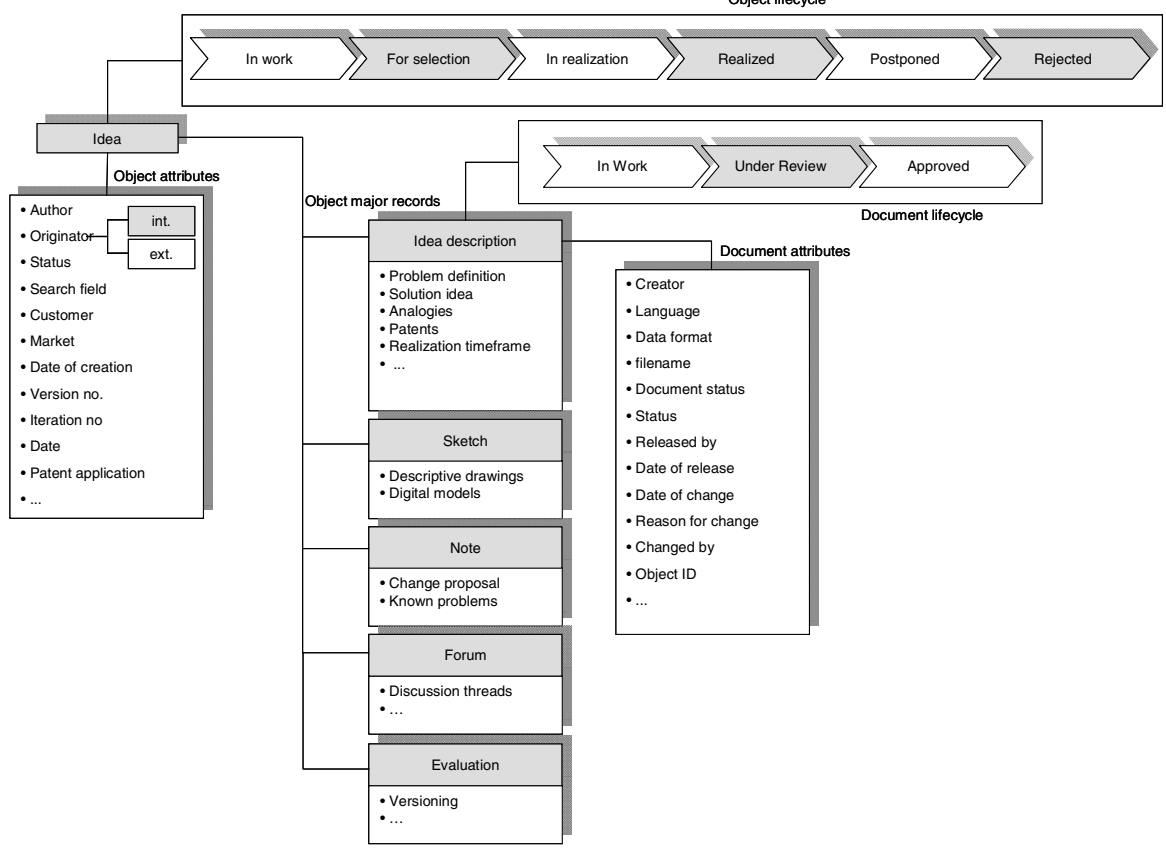

Fig. 7. Data object "idea"

It is obvious, that the complexity itself and setting up a holistic data and process model can overstrain the resources and capabilities of SMEs, as they usually do not have according staff positions. Therefore the created templates can be used and efforts can drastically be reduced. Anyway, it is highly recommended to involve experienced third parties to act as consultants from the early beginning and to focus on the project objectives.

\section{$5 \quad$ Prototypic Implementation}

The last step of the proposed method is the implementation in the given IT system of the company. For the evaluation of the developed innovation process, role and data models and implementation has been performed using PTC Windchill 9.1 with its modules PartsLink and ProjectLink and an Oracle 11g1 data base. Decision for this PDMS has been taken due to its completely web centred approach which does not need a client installation, hence also fulfils the requirement of open innovation needs. 
Besides the different objects, their states and the associated processes, method sheets have been implemented in the "library context" which give additional information about appropriate methods to be used in each of the innovation phases (e.g. method 635 , pest-analysis, ...). The processes themselves have been implemented as (partly) automated workflows to guide the user and ensure a consistent data basis. Fig. 8 depicts the different operations of idea management which are supported by the PDMS.

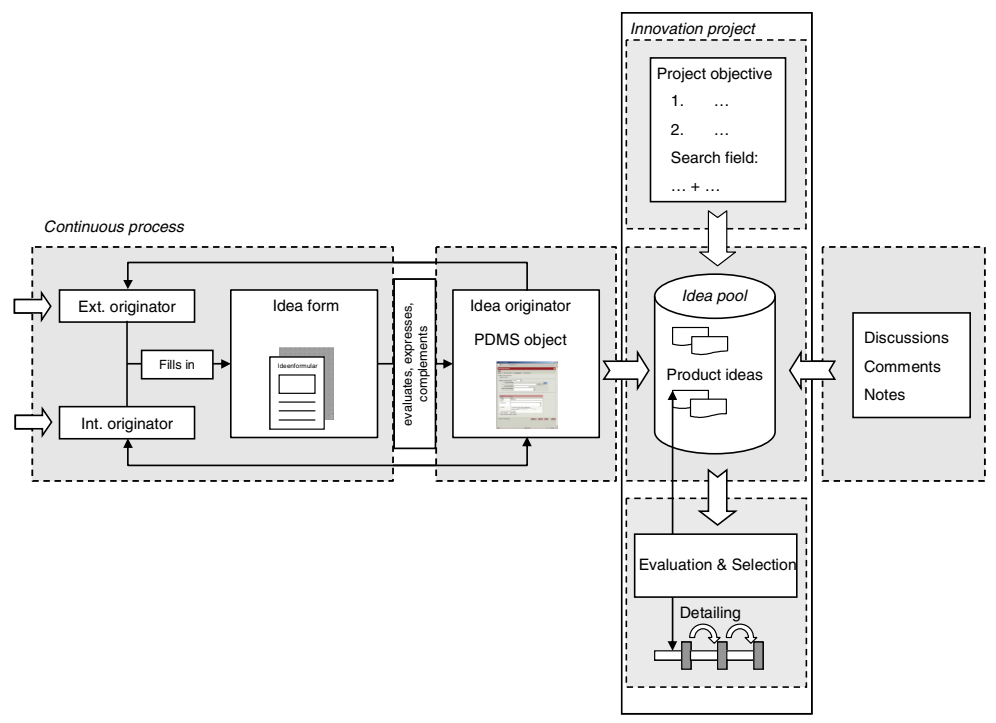

Fig. 8. Process of PDMS idea management

The best practice experience with customers for innovation projects led to the implementation of a project template consisting of all required milestones, activities and deliverables. Not only the project members' workload on the organizational level is reduced by using this predefined template but also the controlling and outcome of different innovation project has shown to be better comparable and evaluable.

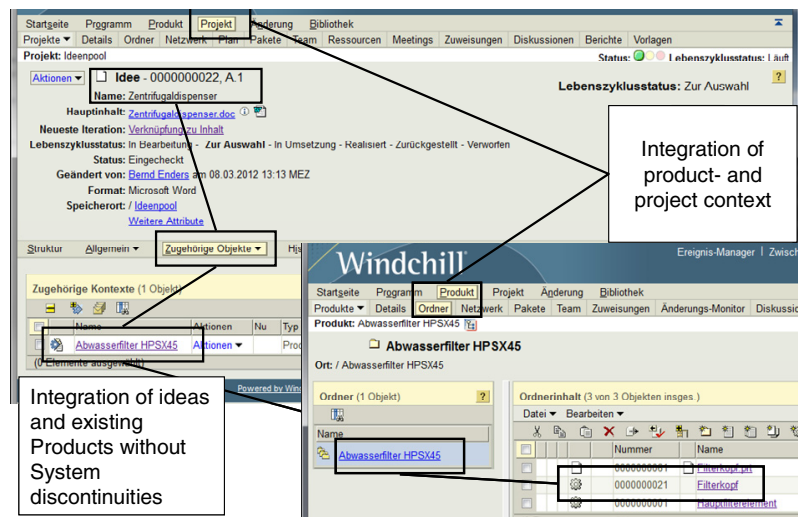

Fig. 9. Windchill implementation for idea and innovation management 
A screenshot of the system implementation is depicted in Fig. 9. Following the PLM approach, it is possible to link ideas (Windchill project context) with existing products (Windchill product context). In case the idea relates to a product improvement which has been initiated by service evaluation or warranty cases, the idea can directly be linked to these reports and thus close the information loop.

\section{Conclusion and Outlook}

This contribution outlined that although PLM has become one of the key aspects in today's business, a lot of further potential has not been unlocked yet. Innovation and idea management have not sufficiently been comprised in an integrated PLM approach to close the gap between strategic considerations prior to the early stages of product planning and the development phases. In order to overcome these drawbacks, an extensive analysis of innovation as well as product planning processes has been conducted as a basis for setting up a generic process and data model to be implemented in PLM supporting software systems. A method and guideline for companies how to determine and implement their innovation and idea management needs has been introduced and illustrated by an exemplary setup in a commercial system.

Further research will be undertaken to create modular data and process models and to provide industry sector specific bundles as an out of the box solution to further decrease the implementation efforts of companies. Besides, the company specific analysis and objective definition will still remain necessary and meaningful.

\section{References}

1. Eigner, M; Stelzer, R. Product Lifecycle Management - Ein Leitfaden für Product Development und Life Cycle Management, 2nd Ed. Berlin; Heidelberg: Springer, 2009.

2. Feldhusen, J. et al.: Development of methods to support the implementation of a PDMS. In: Innovation Life Cycle Engineering and Sustainable Development. Dordrecht: Springer, 2006.

3. Ehrlenspiel, K. Integrierte Produktentwicklung. München; Wien: Carl Hanser, 2003.

4. Pelzer, W. Methodik zur Identifizierung und Nutzung strategischer Technologiepotentiale. Aachen: Shaker, 1999.

5. Schumpeter, J. Theorie der wirtschaftlichen Entwicklung; Eine Untersuchung über Unternehmergewinn, Kapital, Kredit, Zins und den Konjunkturzyklus. Berlin: Duncker \& Humblot, 1934.

6. Meiler, Rudolf Carl: Führungsverhalten und Innovation in kleinen und mittleren Unternehmen. In: Meiler, R. C.(Hrsg.): Mittelstand und Betriebswirtschaft: Beiträge aus Wissenschaft und Praxis. p. 165-182. Wiesbaden: Deutscher Universitäts-Verlag, 1999.

7. Hauschildt, J. Innovationsmanagement, 3. Auflage. München: Franz Vahlen, 2004.

8. Brezing, A. Planung innovativer Produkte unter Nutzung von Design- und Ingenieurdienstleistungen. Aachen: Shaker, 2006.

9. Bleicher, Knut: Das Konzept integriertes Management: Visionen-Missionen-Programme. Frankfurt; New York: Campus, 1999.

10. Völker, R.; Sauer, S.; Simon, M.: Wissensmanagement im Innovationsprozess. Heidelberg: Physica, 2007.

11. Gebhardt, Boris N. B. Abschätzung der Produktdatenmanagement-Systemfähigkeit produzierender Unternehmen. Aachen: Shaker, 2007.

12. Löwer, M. PDM basierte Innovationsplanung im Rahmen eines durchgängigen Product Lifecycle Managements. Aachen, Shaker, 2012. 